\title{
An Integrated Approach to the Prevention of Neglected Tropical Diseases (NTDs): The Way Forward?
}

\author{
By Donald E. Stewart* \\ Budi Laksono ${ }^{\dagger}$ \\ M. J. Park \\ D. X. Wang $^{+}$
}

An integrated approach to health promotion has been widely adopted since the 1986 Ottawa Charter to promote better health and support community-based projects. Complementing the skills of experts, there is a need for community engagement for social and environmental change, with a focus on settings for health promotion initiatives. A sanitation and hygiene project from an Indonesian village setting illustrates the value of using an integrated approach. Village communities took communal action to reduce open defecation by building and using household latrines, while behavioural change was facilitated through health education sessions. The support of "decision-makers" in the community, such as the religious leaders, the village leaders and the army was vital. Medication (Albendazole) was provided to ensure that those infected with soil-transmitted helminth (STH) were effectively treated. The study suggests that an integrated, socio-ecological approach can help to reduce STH infection and improve villagers' health and well-being.

Keywords: Health promotion, Indonesia, Integrated approaches, Parasites, Villages.

\section{Introduction}

Traditionally, researchers interested in prevention or early intervention programs relating to NTDs have emphasised clinical measures of health status, such as presence of parasites, as key indicators of poor health outcomes; and pharmaceutical interventions, such as Albendazole for STH as appropriate preventive drug therapy (WHO 2002). Such an approach, however, neglects social, behavioural and environmental risk factors that, if addressed through effective early intervention or preventative strategies, can directly and indirectly determine clinical outcomes. Importantly, an approach that neglects such "upstream" factors fails to take into account other agencies and strategies that can be woven together to form an integrated, effective and powerful

\footnotetext{
* Professor, School of Medicine, Menzies Health Institute Queensland, Griffith University, Australia.

${ }^{\dagger}$ Director, Wahana Bakti Sejahtera Foundation, Indonesia.

$\$$ Research Fellow, School of Medicine, Menzies Health Institute Queensland, Griffith University, Australia.

${ }^{+}$Research Fellow, Research School of Population Health, The Australian National University, Australia.
} 
methodology to prevent NTDs and, since STH infection is typically a "disease of poverty", improve the health and well-being of some of the poorest people in the world.

Recognition of the influence of social environments on health outcomes was promoted by the international commitment to promoting healthy environments enshrouded in the Declaration of Alma Ata in 1978 (Berkman and Kawachi 2000). The importance of living in a healthy environment, or setting, was further developed in the Ottawa Charter for Health Promotion (WHO 1986) nearly 30 years ago and expanded upon in subsequent Declarations, Statements and Conventions. The Sundsvall Statement on Supportive Environments for Health added further recognition to this approach, stating that a supportive environment is of paramount importance for health and that the two are interdependent and inseparable (WHO 1991). This statement gave recognition to the complex interaction of social factors that determine health and, by implication, directed attention towards multidisciplinary approaches to the prevention of disease.

An integrated approach to the prevention of NTDs means that, in the absence of a preventive vaccine, using an intervention based on known, safe and effective medication and, upon this platform, building mutually supportive and sustaining initiatives, it is possible to effect a sustainable reduction in the global NTD burden of disease. An integrated approach has the potential to reduce, or alleviate the multi-faceted determinants of poor health caused by NTDs. It opens up a wide range of powerful social, psychological, economic, ecological and policy-related instruments that can all be focused on prevention and that can be effectively engaged in attempts to eliminate these debilitating, but neglected tropical diseases.

\section{A Socio-Ecological Approach}

Socio-ecological paradigms of health, which seek to explain the interdependence between social systems, or settings, and population health outcomes, have emerged over the past two to three decades. The WHO has taken the lead in supporting initiatives that address socio-ecological approaches to health promotion and prevention of disease. These models reflect a commitment to the concept of "place" (or habitus) and its significance to health and wellbeing at both individual and population levels. This approach recognises that intrapersonal characteristics, life experiences and dimensions of settings combine to determine our personal capacities for thriving and, potentially, surviving (Berkman et al. 2000, Grossman et al. 2003, Lee and Stewart 2013, Shahar and Priel 2002, Stewart 2014, Svanberg 1998).

Emerging socio-ecological models help to provide a more inclusive and balanced understanding of the determinants of health by recognising both the health risks to which people are exposed, such as inadequate sanitation or polluted drinking water, as well as the protective factors available such as elements of hygiene taught by parents to their children, or externally, such as 
clean piped water, that may buffer those risks (Alvarez-Dardet and Ashton 2005, Antonovsky 1987). Increasingly, empirical studies are investigating the role of socio-ecological environments in determining numerous physical and mental health outcomes, both at individual as well as population levels (Park et al. 2015, Seeman and McEwan 1996, Yen and Syme 1999).

Central to a socio-ecological paradigm of health is the principle that wellbeing is determined by a complex interplay of risk and protective factors derived from the combination of environments, internal dispositions and life experiences to which people are exposed. These factors, some of which are innate and some that are acquired or learned through informal and formal health education, accrue to build our repertoire of coping resources, or our human capital. More broadly, the concept of social capital, as Schuller observes, directs attention towards the social relationships which go to shape the human capital in a community (Schuller 2001), affecting both the individual and the collective "place". Strong social relationships and a sense of connectedness in communities have been shown to have a profound impact on health and consistent evidence indicates that a sense of connectedness is protective of mental and emotional wellbeing (Marmot and Wilkinson 2000).

This article reports on a practical application of a socio-ecological model in Central Java, Indonesia, which targets a key socio-ecological structure (the rural village) with the intention of improving the health of the villagers by an integrated use of medication, simple technology, and building human and social capital to reduce the prevalence of STH, or parasites. The implementation of this project has identified the complex influences of this setting on health and wellbeing, whilst also revealing those factors with potential to change this social context in order to promote better health.

\section{The Problem of Open Defecation}

Globally, WHO/UNICEF estimates that 2.5 billion people lack improved sanitation and that 1.1 billion people ( $15 \%$ of the global population) practice open defecation. The majority of open defecators (949 million) live in rural areas (WHO/UNICEF 2012). Open defecation and poor hygiene contribute to STH (intestinal worm/parasite - Ascaris lumbricoides, Trichuris Trichiura, and hookworm) infections which are among the most common infections worldwide - infecting nearly a third of the world's population and typically affecting the poorest and most deprived communities (WHO 2013). In subSaharan Africa, for example, it is estimated that 215 million people continue to engage in open defecation (Galan et al. 2013). Using country-level data, Galan, Kim and Graham analysed 34 sub-Saharan African countries, finding that between 2005-10 only 3 countries (Ethiopia, Angola and Sao Tome and Principe) had made appreciable inroads into the problem, with a decrease in open defecation of $10 \%$ or more. Based on performance between 2000 and 2010, only one country (Angola) appears likely to end open defecation by 2015 (Galan et al. 2013). 
About $60 \%$ of the rural Indonesian population do not have access to improved sanitation services and over 60 million people practice open defecation. "Improved sanitation" is defined as a sanitation facility that ensures hygienic separation of human excreta from human contact. Joint Monitoring Program figures are supported by findings from the impact evaluation of the Global Scaling-Up Rural Sanitation Project in Indonesia (Cameron and Shah 2010) which estimate that the proportion of the poorest households using open defecation practices $(55 \%)$ is higher than that of the richest $(18 \%)$. A recent World Bank study estimates improved sanitation coverage is only $57 \%$ in Indonesia, still far below the universal sanitation coverage achieved in other Southeast Asian countries such as Thailand and Singapore (World Bank 2008).

\section{Indonesian Village Project}

Previous research in the Central Java village environment in Indonesia identified a number of reasons for the lack of success of many latrine campaigns (Stewart and Laksono 2002). These included the lack of flexibility regarding the availability of water to assist human waste disposal in a country or region that experiences both wet and dry seasons; the need for cultural familiarity, simplicity and ease of use; and the need for a latrine to be affordable by all households. It is also necessary, of course, for a latrine to be effective in terms of health considerations.

Many government or agency sponsored latrine campaigns in developing countries have been unsuccessful or unsustained and these failures are often due to human resources, environment and technology as the introduced latrine technology is not aligned with the human, financial and technical resources available, or the social and cultural environment. The BALatrine (Budi's Amphibious Latrine), however, is a simple but effective household latrine designed to be made by local people using local material in resource-limited developing country villages. It is congruent with the users' habits, funds and environment. It has been developed and modified over more than a decade to address these issues and to ensure that existing unsanitary and unhygienic customs and habits are discouraged and that villagers, through ownership and the design and implementation of the BALatrine, adopt new healthier sanitary toilet habits.

The BALatrine is a standard squat latrine model (Figure 1) - with the difference that it can accommodate the availability or lack of water together with relatively low maintenance, as far as cleaning is concerned. The amphibious closet may be removed when flushing is not feasible and human waste is deposited directly into the septic tank hole. Although not ideal, latrines built according to these specifications are preferred to open defecation and pollution of natural waterways. 
Figure 1. The "BALatrine" Showing Removable Porcelain Bowl

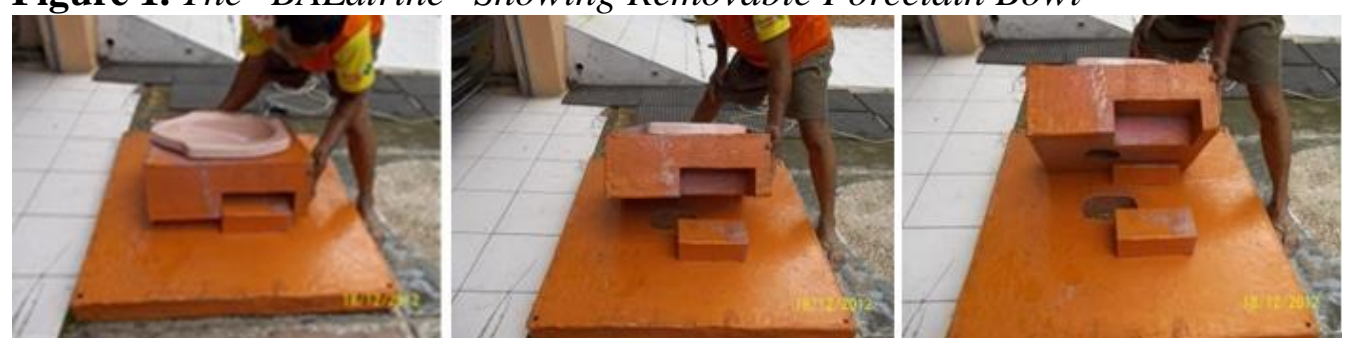

In addition to a simple "technical" intervention, and congruent with key features of a socio-ecological approach, the BALatrine is designed to be adopted at the household or family level and therefore, through the process of empowerment, requires the engagement of householders at a number of points. This includes, for example, their personal ownership of the decision to invest time and money in a household latrine; to install it; and to use and maintain it in a hygienic and healthy manner. It effectively shifts villagers from a precontemplation, or contemplation stage of change, to participatory action and engagement. At the household level, when a family makes the decision and the financial investment to build a family latrine, the owner will choose to build it near his house. The personal ownership of the latrine and the investment of both time, effort and resources usually means regular use and better maintenance. For example, when a child uses the latrine and does not flush it, the whole family accepts responsibility for latrine hygiene. This in turn will mean better hygiene and better health for the whole family.

The socio-ecological approach leads us to emphasise notions of empowerment (households being the active creator rather than the passive recipient of the latrine) as well as being active participants in the planning and implementation of the latrine intervention. Participation in community activities is recognised as a protective factor in relation to health outcomes.

Underlying the project is the fundamental concept of equity with the active engagement of all village families or households in the project. This total village approach (identified as "Katajaga" in our project) means there is no divide between rich and poor - rather, it is a total village engagement, and total village gain.

Another component of the socio-ecological approach is that it encourages a multi-strategic framework with a wide range of influential individuals ("decision-makers") enrolled in supporting the project, together with relevant strategies. For example, the village Imam (religious leader) was approached to engage his support so that he could encourage cleanliness and hygiene as important aspects of a good spiritual and ethical lifestyle. Furthermore, each village is associated with a member of the Indonesian armed forces and has links to the army through this "Babinda" or local military representative. In our villages the military took on a key role as they assisted the less able, such as elderly widows or those who lacked the strength or capacity to construct the latrine in the village.

Most importantly, the project engaged the support of the village leaders and headman and these groups were highly influential in ensuring that village 
households participated in the project. They were also significant in motivating villagers to attend the health education sessions provided to explain the benefits of reducing open defecation and raising awareness of the importance of personal hygiene.

\section{Conclusions}

We chose to pay close attention to the social and environmental factors (sometimes called the social determinants of health) that affect the health status of the villagers and recognized that health is a matter that goes beyond the provision of health services. In the village there are contextual issues affecting health outcomes - such as environmental conditions, housing, clean water, health education, sanitation infra-structure - in addition to access to health-care services.

Our plan has been to try and make the village a healthy setting in which to live and bring up a family. We did not treat individuals in isolation from the larger social networks in which they live, work and play. Although we also focussed on both the individual behavioural risk factors and the broader village environment. Fundamentally, we considered that the village environment should support and enhance health and not be a risk to the health of the villagers.

An integrated approach recognises the importance of having appropriate multi-level (village/district/province) policy settings. It ensures that a sanitation environment with household latrines that make 'the healthy choice the easy choice' are created. It facilitates, supports and strengthens community action with culturally accepted and appropriate "influentials". It ensures that information and education to develop personal hygiene skills is provided. It also engages the health services, through chemotherapy in the case of STH, in treatment regimes that are re-oriented to work together with community actions to combat reinfection. Our sanitation and hygiene project illustrates the effectiveness of an integrated approach to the prevention of disease and its potential as the way forward.

\section{Acknowledgements}

We are grateful to all the residents of the villages, to the village heads, the research assistants, and the mayor of Semarang City. This work would not have been possible without generous support from the UBS Optimus Foundation.

\section{References}

Alvarez-Dardet C, Ashton JR (2005) Saluting good health. Journal of Epidemiology and Community Health. 59: 437.

Antonovsky A (1987) Unraveling the mystery of health: How people manage stress and stay well. San Francisco, CA, US: Jossey-Bass.

Berkman LF, Glass T, Brissette I, Seeman TE (2000) From social integration to health: Durkheim in the new millennium. Social Science and Medicine 51: 843-857. 
Berkman LF, Kawachi I (2000) Social Epidemiology. New York: Oxford University Press.

Cameron L, Shah M (2010) Scaling Up Rural Sanitation: Findings from the Impact Evaluation Baseline Survey in Indonesia. Water and Sanitation Project Technical Paper, November 2010.

Galan DI, Kim SS, Graham JP (2013) Exploring changes in open defecation prevalence in sub-Saharan Africa based on national level indices. BMC Public Health 13: 527.

Grossman AW, Churchill JD, McKinney BC, Kodish IM, Otte SL, Greenough WT (2003) Experience effects on brain development: possible contributions to psychopathology. Journal of Child Psychology and Psychiatry 44: 33-63.

Lee PC, Stewart DE (2013) Does a socio-ecological school model promote resilience in primary schools? Journal of School Health 83: 795-804.

Marmot M, Wilkinson R (2000) Social determinants of health. Health Promotion International 15(1): 87-91.

Park MJ, Laksono B, Sadler R, Clements A, Stewart D (2015) Household latrines to control environmental contamination and helminthiasis: an exploratory study in Indonesia. International Journal of Social Science and Humanity 5(5/May): 429-435.

Schuller T (2001) The Complementary Roles of Human and Social Capital. Canadian Journal of Policy Research 2(1): 18-24.

Seeman TE, McEwen BS (1996) The impact of social environment characteristics on neuroendocrine regulation. Psychosomatic Medicine 58: 459-471.

Shahar G, Priel B (2002) Positive life events and adolescent emotional distress: in search of protective-interactive processes. Journal of Social and Clinical Psychology 21(6): 645-668.

Stewart D (2014) Resilience: an entry point for African health promoting schools? Health Education 114(3): 197-207.

Stewart D, Laksono B (2002) Helminth infection, human waste and appropriate technology: An Indonesian case study. Environmental Health 2(4): 46-52.

Svanberg OG (1998) Attachment, resilience, and prevention. Journal of Mental Health 7(6): 543-579.

WHO (1986) The Ottawa Charter for Health Promotion. First International Conference on Health Promotion, Ottawa, 21 November 1986.

WHO (1991) Sundsvall Statement on Supportive Environments for Health. Third International Conference on Health Promotion, Sundsvall, Sweden, 9-15 June 1991.

WHO (2002) Prevention and control of schistosomiasis and soil-transmitted helminthiasis: report of a WHO expert committee. WHO Technical Report 912: $1-57$.

WHO (2013) Intestinal worms. Retrieved from http://goo.gl/6zjthj. [Accessed: 20 October 2013]

WHO/UNICEF (2012) Joint monitoring report 2012: Progress on drinking water and sanitation. Retrieved from http://goo.gl/EhwL86. [Accessed: 20 March 2013]

World Bank (2008) Economic impacts of sanitation in Southeast Asia: A four-country study conducted in Cambodia, Indonesia, the Philippines and Vietnam under the Economics of Sanitation Initiative (ESI). Jakarta: The World Bank.

Yen IH, Syme SL (1999) The social environment and health: a discussion of the epidemiologic literature. Annual Review of Public Health 20: 287-308. 
